Original Research Article

\title{
Treatment outcome of tuberculosis patients under directly observed treatment short-course and factors affecting the outcome in tertiary care hospital
}

\author{
Parigna R. Trivedi ${ }^{1}$, Tejas M. Khakhkhar ${ }^{2 *}$
}

${ }^{1}$ Student, ${ }^{2}$ Department of Pharmacology, Gujarat Adani Institute of Medical Sciences, Bhuj, Gujarat, India

Received: 21 February 2019 Accepted: 28 March 2019

*Correspondence to: Dr. Tejas M. Khakhkhar, Email: tejaskhakhar@gmail.com

Copyright: (C) the author(s), publisher and licensee Medip Academy. This is an openaccess article distributed under the terms of the Creative Commons Attribution NonCommercial License, which permits unrestricted noncommercial use, distribution, and reproduction in any medium, provided the original work is properly cited.

\begin{abstract}
Background: Revised National Tuberculosis Control Programme (RNTCP) based on Directly Observed Treatment Short-course (DOTS) strategy has been made available in entire country by March 2006. Given high rate of unfavourable treatment outcomes reported in some provinces, there is a need to analyse outcomes and identify possible trends and associated risk factors that can help for improvement in RNTCP.

Methods: After getting Institutional Ethics Committee (IEC) approval, total of 76 cases diagnosed and treated for Tuberculosis (TB) under Category I of RNTCP were recruited from January to March 2017. All patients were followed up for six months from date of initiating the treatment. The data was obtained from TB treatment register, by patient visit and regular follow-up. The information collected include age and gender of patient, category of treatment, date of treatment initiation, initial sputum conversion, outcome of treatment and date of outcome.

Results: Out of total 76 patients, $64(84.21 \%)$ were cured, $5(6.57 \%)$ were lost to follow-up, $4(5.26 \%)$ were failed to treat, $1(1.32 \%)$ patient was died, $1(1.32 \%)$ patient had completed treatment but status was unknown and $1(1.32 \%)$ patient was not evaluated because of transfer. Overall treatment outcome of TB patients under DOTS was matching goal of RNTCP with cure rate of $84.21 \%$.

Conclusions: Efforts by DOT providers, adequate patient education, motivating ones in need can bring positive outcomes. In this region, DOTS center is at good working condition in terms of functionality as well as ethically. Gender, age group, residence and initial culture colony did not significantly affect treatment outcome.
\end{abstract}

Keywords: DOTS, Factors, Treatment outcome, Tuberculosis

\section{INTRODUCTION}

Tuberculosis (TB) remains a major global health problem and ranks the second leading cause of death from an infectious disease worldwide.

India is the highest TB burden country accounting for more than one fifth of the global burden of tuberculosis. It is estimated that about $40 \%$ of the Indian population is infected with TB bacteria, the vast majority of whom have latent rather than active $\mathrm{TB} .^{2}$
To tackle this problem, World Health Organization (WHO) has implemented the Standardised Directly Observed Treatment Short-course (DOTS) under Stop TB Strategy for TB prevention and control. ${ }^{3}$

Revised National Tuberculosis Control Programme (RNTCP) based on the DOTS strategy has been made available in the entire country by March 2006. DOTS is a strategy to ensure cure by providing the most effective medicine and confirming that it is taken under directs supervision. The DOTS strategy has five components: political will, diagnosis by quality assured sputum smear 
microscopy, adequate supply of quality assured short course chemotherapy drugs, directly observed treatment and systematic monitoring. ${ }^{4}$ The grass root level link between program and beneficiaries in RNTCP are DOTS centers. To ensure a good program, a well-trained and adequately equipped DOT provider is needed. Varied groups of people from the health or community can be DOT providers, who supervise TB treatment. ${ }^{5}$

In the hospital, DOTS clinic is operating under RNTCP, in which patients are diagnosed with tuberculosis by examination of morning sputum smears by modified Ziehl-Neelsen staining for the presence of Acid-Fast Bacilli (AFB). ${ }^{6}$

DOTS also aim to decrease the occurrence of primary and acquired drug resistance and relapse besides the primary association with treatment success rate. Hence preventing the spread of tuberculosis infection and preventing the emergence of new drug-resistant strains are among the main focus area. ${ }^{7}$

RNTCP has achieved improved cure rates and a success rate of $88 \%$ among new smear positive cases was reported in $2011 .^{8-10}$ The unfavourable outcomes under the RNTCP are death, default and failures. In 2011, death rate, default rate and failure rate among new smear positive cases was reported as $4 \%, 6 \%$ and $2 \%$ respectively. ${ }^{11}$

The factors affecting outcome include gender, alcoholism, treatment after default, poor knowledge of tuberculosis, irregular treatment and socioeconomic status. ${ }^{12,13}$ Other factors related to the service providers like difficulty in accessing health facility, non-governmental DOT center and previous treatment from non-RNTCP providers have also been identified as reasons for non-completion of treatment. ${ }^{14}$

Given the high rate of unfavourable treatment outcomes reported in some provinces, there is a need to analyse outcomes and identify possible trends and associated risk factors that can help for further improvement in RNTCP. Very few studies have been done in the recent past focusing on treatment outcome and factors affecting the outcome particularly in this region. This study would help to identify specific issues in different phases of treatment that lead to the outcome of the treatment.

\section{METHODS}

After approval of Institutional Ethics Committee (IEC), this prospective, observational study was carried out in G.K. General Hospital, a tertiary care hospital in BhujKutch, Gujarat, India. Prior permission to conduct the study was also obtained from the Head of TB and Chest Disease Department.

The patients diagnosed and treated for TB under Category I of The Revised National Tuberculosis Control Program (RNTCP) from above hospital were recruited.

\section{Inclusion criteria}

- All patients willing to participate in the study \& giving the informed consent form.

- $\quad$ Patients of all age, both genders.

\section{Exclusion criteria}

- Pregnant women.

A total of 76 cases falling in above criteria were recruited after getting IEC approval from January to March 2017. All patients were followed up for the duration of six months from the date of initiating the treatment. The data was obtained from the TB treatment register as well as by patient visit and regular follow-up. The information collected include age and gender of the patient, category of treatment, date of initiation of treatment, initial sputum conversion, outcome of treatment and date of outcome in pretested case record form. Date of outcome was the date on which the last dose of drug was taken.

\section{The criteria for the outcome of treatment were as follows ${ }^{15}$}

- Cured: A pulmonary TB patient with bacteriologically confirmed TB at the beginning of treatment who was smear- or culture-negative in the last month of treatment and on at least one previous occasion.

- Completed treatment: A TB patient who completed treatment without evidence of failure but with no record to show that sputum smear or culture results in the last month of treatment and on at least one previous occasion were negative, either because tests were not done or because results are unavailable.

- Died: A TB patient who died from any cause during treatment.

- Failed: A TB patient whose sputum smear or culture is positive at month 5 or later during treatment.

- Lost to follow-up: A TB patient who did not start treatment or whose treatment was interrupted for two consecutive months or more.

- Not evaluated: A TB patient for whom no treatment outcome is assigned. This includes cases 'transferred out' to another treatment unit as well as cases for whom the treatment outcome is unknown to the reporting unit.

\section{Statistical analysis}

The confidentiality of patients was maintained during the study. Data was analysed using SPSS for windows, trial version 20 using chi-square test. To ensure quality of the data, two individuals independently cross-checked each entry. P-value $\leq 0.05$ was considered as significant.

\section{RESULTS}

Out of total 76 patients, $64(84.21 \%)$ were cured, $5(6.57 \%)$ were lost to follow-up, $4(5.26 \%)$ were failed to treat, 1 
$(1.32 \%)$ patient was died, $1(1.32 \%)$ patient had completed treatment but status was unknown and 1 (1.32\%) patient was not evaluated because of transfer (Table 1).

Table 1: Treatment outcome of TB patients under DOTS.

\begin{tabular}{|ll|l|}
\hline Outcome & No. of patients & Percentage \\
\hline Cured & 64 & 84.21 \\
\hline $\begin{array}{l}\text { Completed } \\
\text { treatment }\end{array}$ & 1 & 1.32 \\
\hline Died & 1 & 1.32 \\
\hline Failed & 4 & 5.26 \\
\hline Lost to follow-up & 5 & 6.57 \\
\hline Not evaluated & 1 & 1.32 \\
\hline
\end{tabular}

Table 2: Factors associated with treatment outcome.

\begin{tabular}{|c|c|c|c|c|}
\hline Factors & & $\begin{array}{l}\text { Outcome } \\
\text { - cured } \\
(64)\end{array}$ & $\begin{array}{l}\text { Outcome - } \\
\text { other than } \\
\text { cured (12) }\end{array}$ & $\begin{array}{l}\text { P- } \\
\text { value }\end{array}$ \\
\hline \multirow{2}{*}{ Gender } & Male & 47 & 9 & \multirow{2}{*}{0.912} \\
\hline & Female & 17 & 3 & \\
\hline \multirow{2}{*}{ Age } & $\leq 40$ & 37 & 5 & \multirow{2}{*}{0.4490} \\
\hline & $>40$ & 27 & 7 & \\
\hline \multirow{2}{*}{ Residence } & Urban & 26 & 3 & \multirow{2}{*}{0.1533} \\
\hline & Rural & 38 & 9 & \\
\hline \multirow{2}{*}{$\begin{array}{l}\text { TB with } \\
\text { HIV }\end{array}$} & Yes & 1 & 0 & \multirow{2}{*}{0.3237} \\
\hline & No & 62 & 13 & \\
\hline \multirow{2}{*}{$\begin{array}{l}\text { Personal } \\
\text { habit }\end{array}$} & Yes & 23 & 8 & \multirow{2}{*}{0.0234} \\
\hline & No & 41 & 4 & \\
\hline \multirow{2}{*}{$\begin{array}{l}\text { Initial } \\
\text { culture } \\
\text { colony }\end{array}$} & $\begin{array}{l}3+\text { or } \\
2+\end{array}$ & 40 & 7 & \multirow{2}{*}{0.1907} \\
\hline & $\begin{array}{l}1+\text { or } \\
\text { scanty }\end{array}$ & 20 & 6 & \\
\hline
\end{tabular}

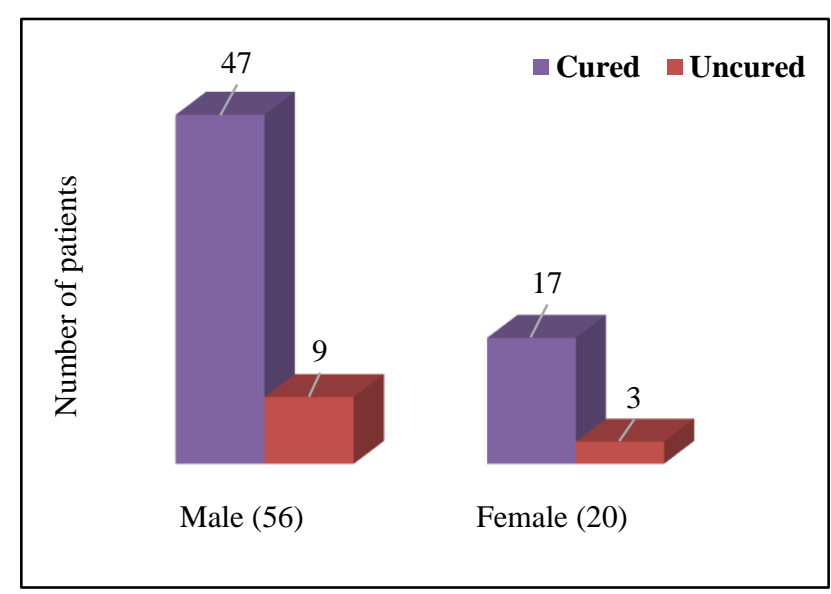

Figure 1: Gender distribution with treatment outcome.

As shown in Table 2, out of 56 male patient assigned in this study 47 were cured while out of total 20 female patient 17 were cured, while 9 male and 3 female uncured $(\mathrm{P}=0.912)$ (Figure 1).

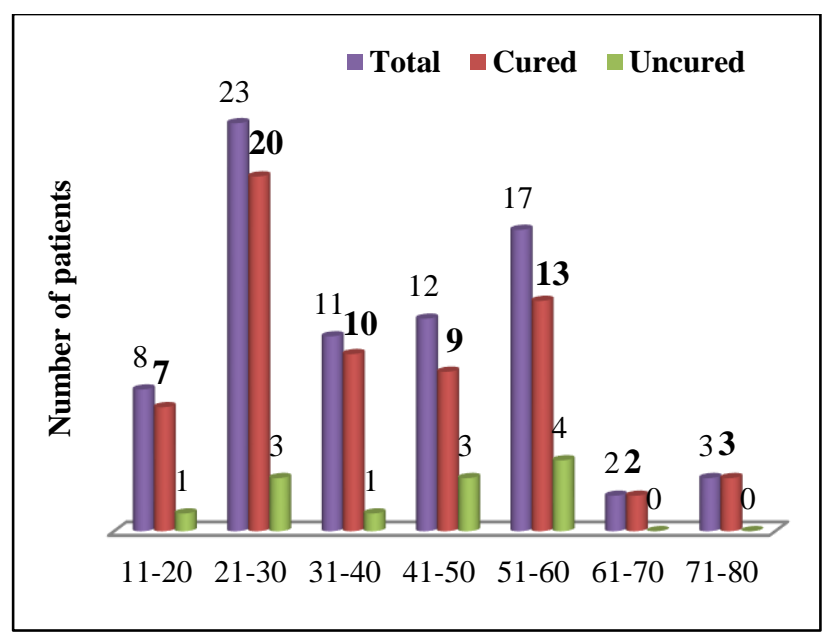

Figure 2: Age distribution with treatment outcome.

A total of 42 patients whose age was $\leq 40$; out of which 37 had positive results while 5 had negative results. While total of 34 patients were above age of 40; out of which 27 were cured while 7 had other outcome $(\mathrm{P}=0.4490)$. The highest number of the patients $23(30.26 \%)$ were from 21 30 age group followed by $17(22.36 \%)$ in 51-60 age group (Figure 2). The overall mean age and standard deviation (SD) was $40.11 \pm 15.94$ (range 16-75) years.

Out of 29 patients from urban area, 26 were cured $\& 3$ not cured; while out of 47 patients residing in rural area, 38 were cured and 9 uncured $(\mathrm{P}=0.1533)$.

Out of 76 recruited patients, only one was co-infected with HIV, who got cured while out of rest 75 patients, 62 got cured while 13 were not cured $(\mathrm{P}=0.3237)$.

Total 31 patients had personal habits (of smoking, tobacco or alcohol); of which, 23 were cured while 8 not cured and 45 had no any personal habits; of which, 41 were cured while only 4 had other outcome. This was also found statistically significant $(\mathrm{P}<0.05)$ (Figure 4 and 5).

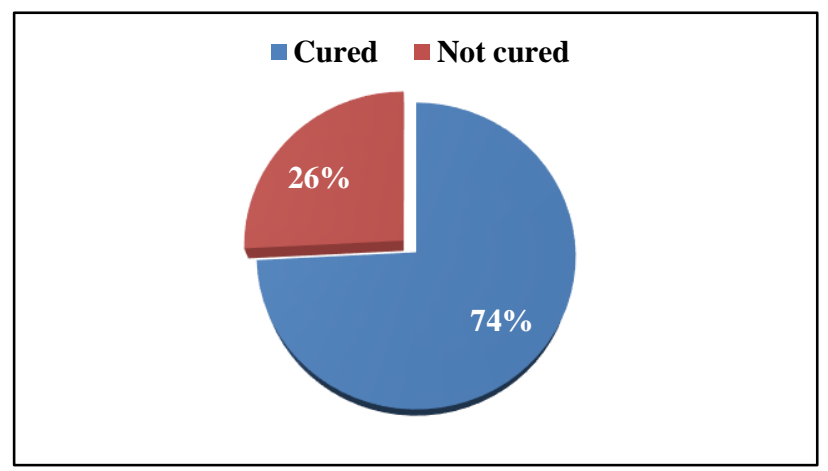

Figure 4: Relation of outcome of patients with personal habits.

Total 47 patients with initial colony culture more than $3+$ or $2+$ were recruited of which, 40 were cured while 7 had other outcomes while 26 patients had colony culture of $1+$ 
of which, 20 were cured and 6 had other outcome $(\mathrm{P}=1907)$.

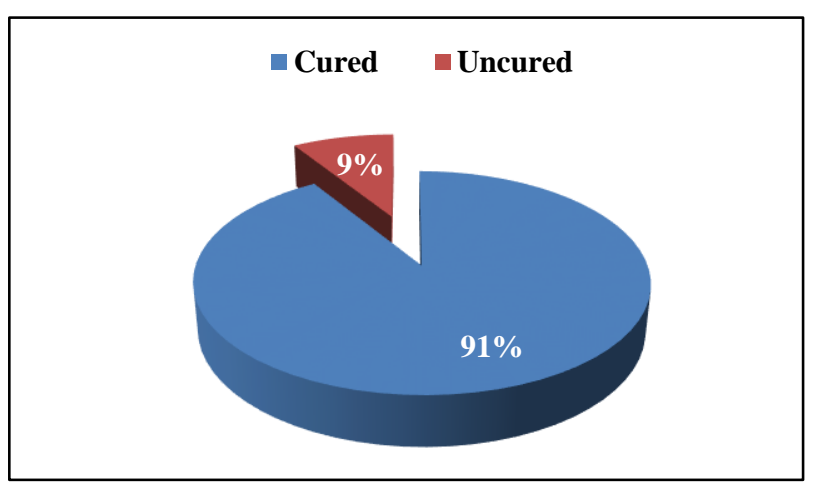

Figure 5: Relation of outcome of patients without personal habits.

\section{DISCUSSION}

In the present study, a total of 76 patients were recruited; of which, 64 were cured hence the success rate was $84.21 \%$ which was similar to the results found in the study done by Shunmugam et al, in Kanyakumari with success rate of $84.59 \% .{ }^{16}$ Also, in a study in southern Ethiopia with similar results treatment success rate of the TB patients was $85.2 \% .{ }^{17}$ This success rate hence by proved the good adherence to treatment and enough efforts by the providers in doing the same.

The 4 patients had completed the treatment but failed to in sputum conversion. Thus, failure rate was $5.26 \%$. The number of lost to follow-up patients was $5(6.57 \%)$ as the treatment of these patients was interrupted for more than 2 months. The noted death rate of this study was $1.32 \%$ as one patient was died during the period of treatment. One patient was transferred out to another treatment center; hence not evaluated outcome was $1.32 \%$. And one patient whose treatment was complete, but the result was not available until the completion of this study, so constituted rate was also $1.32 \%$.

This findings suggest that the rates of unsuccessful treatment can further be reduced by studying the various underlying factors. Out of total 76 cases, majority of the patients $(56,73.68 \%)$ were male and only $20(26.31 \%)$ were female in contrast to previous studies done in Gambella et al, and Gondar et al. ${ }^{18,19}$ This could be due to underutilization of the DOTS service by females or higher proportion of males being exposed to the infection in the study area. A study conducted in Bangladesh on access to TB diagnosis and treatment also documented that women have poorer access to public outpatient clinics than men. ${ }^{20}$ The treatment failure rate was $16 \%$ and $15 \%$ in male female patients respectively; which was not a significant variation.

In the present study, 42 patients were below or equal to age of 40 , which constitutes most productive age groups and may pose challenges to the social and economic development of the community in the area and the nation at large. Failure rate in patients below or equal to age of 40 was $11.9 \%$ while in patients above age of 40 was $21.87 \%$ which was quite higher but statistically found not significant. Older age has been reported to be a risk factor for death, partly due to co-infection and general physiological deterioration with age and thus it is crucial to exercise close monitoring of TB treatment also in older patients. $^{21}$

The number of patients residing in rural area were more 47 (61.84\%), as compared to urban area 29 (38.15\%). Also, patients residing in urban area showed higher cure rate $(89.65 \%)$ compared to patients residing in rural area $80.85 \%$ but this was not statistically significant. These findings were not similar with the study done by Melese et al, in which, majority of the patients $(60.8 \%)$ were urban residents; out of which only $18 \%$ were cured. $^{22}$

In this study the failure rate in patients co-infected with HIV was not found this was an unexpected result but it could be because only single patient was recruited TB with HIV and that due to good adherence had positive outcome. While in study done by Ambadekar et al, cure rate was lower $(72 \%)$ as well as death rate was higher (19\%) compared to patient without concomitant disease. ${ }^{23}$

Patients with personal habits like smoking, tobacco chewing, or alcohol consumption had high failure rates and constituted around $25.8 \%$ against just $8.88 \%$ in the ones who didn't have any personal habits, and this was also found statistically significant $(\mathrm{P}<0.05)$. Thus, personal habits have a significant contribution to the outcome failure. A study done by Jain et al, also showed that treatment was not successful in patients with smoking and alcohol consumption. ${ }^{24}$ A similar study conducted by Suryakant et al, found that smoking was significantly related to TB germ conversion time elongation in patients who were on anti-TB drug therapy. ${ }^{25}$ Smoking is closely associated with drinking, and is strongly inversely associated with educational status. Furthermore, tobacco chewing, and alcohol consumption were found to be negative predictors of successful treatment outcome which may be due to suppression of immunity by nicotine and altered drug metabolism. This may adversely affect plasma levels and increase frequency of adverse drug reactions (ADRs) and frequent ADRs have a propensity to drug interruptions and discontinuation which in turn increase chances of unsuccessful outcome. ${ }^{26}$ Thus, a patients selfawareness and their personal habits will always will a primary concern for the outcome of the DOTS treatment. No amount of efforts from the DOTS providers will do good if a patient not show active participation towards their own cure. Hence, single sided efforts won't be of able to provide the expected results.

Initial culture colony of +3 and +2 had failure rates of $14.89 \%$ while $1+$ or scary had $23 \%$ this was also an unexpected results which could be due high attention paid 
to one's with colony cultures and a vigorous course of observation was rented on them. In contrast to this, a study done in Nigeria showed that patients with higher sputum grading before treatment have an increased risk of poor outcome and the conversion rate and success rate also reduced with increased sputum grading. ${ }^{27}$

The period of the study ( 9 months) was one of the limitations of the study. Authors have not included other concomitant disease status like diabetes, radiological extent of disease and culture conversion after intensive phase; which may affect the treatment outcome. Culture and sensitivity test for the treatment failure cases can be helpful but it was not carried out in the present study.

\section{CONCLUSION}

It can be concluded that overall treatment outcome of TB patients under DOTS was matching the goal of RNTCP with cure rate of $84.21 \%$. Efforts by the DOT providers in observing the daily intake of drugs, educating the impact of long treatment, motivating the ones in need can bring positive outcomes. In our region, DOTS center is at good working condition in terms of functionality as well as ethically. Gender, age group, residence and initial culture colony did not significantly affect the treatment outcome. Adequate education to the patients as well as family members is recommended on personal habits affecting treatment strategies. Other obstacles for successful outcome are long duration of treatment and number of pills per day. Further research involving more number of patients for longer duration and involving different DOTS centers will impact the relevance of study results.

\section{Funding: No funding sources}

Conflict of interest: None declared

Ethical approval: The study was approved by the Institutional Ethics Committee

\section{REFERENCES}

1. World Health Organization. Global Tuberculosis report. Available at: www.who.int/iris/bitstream/10665/75938/1/9789241 564502_eng.pdf.

2. Ramos JM, Reyes F, Facin R, Tesfamariam A. Surgical lymph node biopsies in a rural Ethiopian hospital: histopathologic diagnoses and clinical characteristics. Ethiopian Med J. 2008;46(2):173-8.

3. Chaulk CP, Kazandjian VA. Directly observed therapy for treatment completion of pulmonary tuberculosis: consensus statement of the public health tuberculosis guidelines panel. JAMA. 1998;279(12):943-8.

4. Kishore J. Revised national tuberculosis control program: DOTS strategy including DOTS plus. National health programs of India. 10th ed. New Delhi: Century publications, 2012:231-33.

5. Kanungo S, Khan Z, Ansari MA, Abedi AJ. Assessment of Directly Observed Treatment in
Revised National Tuberculosis Control Programme: A Study from North India. J Nat Sci Biol Med. 2017;8(2):171-5.

6. Chennaveerappa PK, Siddharam SM, Halesha BR, Vittal BG, Jayashree N. Treatment outcome of tuberculosis patients registered at DOTS centre in a teaching hospital, South India. Int J Biol Med Res. 2011;2(2):487-9.

7. Ditah IC, Reacher M, Palmer C, Watson JM, Innes J, Kruijshaar ME, et al. Monitoring tuberculosis treatment outcome: analysis of national surveillance data from a clinical perspective. Thorax. 2008;63(5):440-6.

8. Vasudevan K, Jayakumar N, Gnanasekaran D. Smear conversion, treatment outcomes and the time of default in registered tuberculosis patients on RNTCP DOTS in Puducherry, Southern India. J Clin Diag Res. 2014 Oct; 8(10):JC05.

9. Singh A, Bhardwaj A, Mukherjee AK, Arya R, Mithra P. current status of timing of treatment interruption and pattern of default among Tuberculosis patients on directly observed treatment. J Dr. NTR Univ Health Sci. 2013 Jul 1;2(3):177.

10. TB India 2013- RNTCP status report. Central TB Division, Directorate General of Health Services Ministry of Health and Family Welfare. Government of India. 2013.

11. Pardeshi GS. Time of default in tuberculosis patients on directly observed treatment. J Global Infect Dis. 2010 Sep;2(3):226.

12. Jha UM, Satyanarayana S, Dewan PK, Chadha S, Wares F, Sahu S, et al. Risk factors for treatment default among re-treatment tuberculosis patients in India, 2006. PLoS One. 2010 Jan 25;5(1):e8873.

13. Santha T, Garg R, Frieden T, Chandrasekaran V, Subramani R, Gopi P, et al. Risk factors associated with default, failure and death among tuberculosis patients treated in a DOTS programme in Tiruvallur District, South India, 2000. Int J Tuberculosis Lung Dis. 2002;6(9):780-8.

14. Gopi PG, Vasantha M, Muniyandi M, Balasubramanian R, Narayanan PR. Risk factors for non-adherence to directly observed treatment (DOT) in a rural tuberculosis unit, South India. Indian J Tuberculosis. 2007;54(2):66-70.

15. World health organization. 2014. Global Tuberculosis report. Available at: http://reliefweb.int/sites/reliefweb.int/files/resources/t b14_web_ready_v3.pdf.

16. Shunmugam M, Pratheeban J, Kumar PS, Ganesan M. A retrospective study on treatment outcomes of tuberculosis patients under RNTCP in tertiary care centre- Kanyakumari. J Evid Based Med Healthcare. 2017;4(2):59-63.

17. Gebrezgabiher G, Romha G, Ejeta E, Asebe G, Zemene E, Ameni G. Treatment Outcome of Tuberculosis Patients under Directly Observed Treatment Short Course and Factors Affecting Outcome in Southern Ethiopia: A Five-Year 
Retrospective Study. PLoS One 2016;11(2):e0150560.

18. Sisay S, Mengistu B, Erku W, Woldeyohannes D. Directly Observed Treatment Short-course (DOTS) for tuberculosis control program in Gambella Regional State, Ethiopia: ten years experience. BMC Res Notes. 2014 Dec;7(1):44.

19. Tessema B, Muche A, Bekele A, Reissig D, Emmrich F, Sack U. Treatment outcome of tuberculosis patients at Gondar University Teaching Hospital, Northwest Ethiopia. A five-year retrospective study. BMC Public Health. 2009 Dec;9(1):371.

20. Begum V, De Colombani P, Das Gupta S, Salim Md A H, Hussain H, Pietroni M, et al. Tuberculosis and patient gender in Bangladesh: sex differences in diagnosis and treatment outcome. Int $\mathrm{J}$ Tuberculosis Lung Dis. 2001 Jul 1;5(7):604-10.

21. Caylà JA, Caminero JA, Rey R, Lara N, Valles X, Galdós-Tangüis H. Current status of treatment completion and fatality among tuberculosis patients in Spain. Int J Tuberculosis Lung Dis. 2004 Apr 1;8(4):458-64.

22. Melese A, Zeleke B, Ewnete B. Treatment outcome and associated factors among tuberculosis patients in Debre Tabor, Northwestern Ethiopia: a retrospective study. Tuberculosis Res Treatment. 2016;2016.

23. Ambadekar NN, Zodpey SP, Soni RN, Lanjewar SP. Treatment outcome and its attributes in TB-HIV coinfected patients registered under Revised National
TB Control Program: a retrospective cohort analysis. Public Health. 2015;129(6):783-9.

24. Jain K, Desai M, Solanki R, Dikshit RK. Treatment outcome of standardized regimen in patients with multidrug resistant tuberculosis. J Pharmacol Pharmacotherapeut. 2014;5(2):145.

25. Prasad R, Suryakant RG, Singhal S, Dawar R, Agarwal GG. A case-control study of tobacco smoking and tuberculosis in India. Ann Thoracic Med. 2009;4(4):208.

26. Prajapati K, Mishra V, Desai M, Solanki R, Naik P. Treatment outcome of patients having extensively drug-resistant tuberculosis in Gujarat, India. Int $\mathbf{J}$ Mycobacteriol. 2017 Jul 1;6(3):289.

27. Nwokeukwu HI, Awujo DN, Emma-Ukeagbu U. Association of sputum conversion and outcome with initial smear grading among new smear positive Tuberculosis patients in a Tertiary Health Facility, South East Zone, Nigeria. J Dental Med Sci. 2013;4(6):2279-0853.

Cite this article as: Trivedi PR, Khakhkhar TM. Treatment outcome of tuberculosis patients under directly observed treatment short-course and factors affecting the outcome in tertiary care hospital. Int $\mathbf{J}$ Basic Clin Pharmacol 2019;8:981-6. 